Article

\title{
Synthesis of Ag nanoparticles for the electrochemical detection of anticancer drug flutamide
}

\author{
Farzaneh Ahmadi a, Jahan Bakhsh Raoof a,*, Reza Ojani a, Mehdi Baghayeri a, \\ Moslem Mansour Lakouraj ${ }^{b}$, Hamed Tashakkorian ${ }^{b}$ \\ a Electroanalytical Chemistry Research Laboratory, Department of Analytical Chemistry, Faculty of Chemistry, University of Mazandaran, Babolsar, Iran \\ b Department of Organic Chemistry, Faculty of Chemistry, University of Mazandaran, Babolsar, Iran
}

\section{A R T I C L E I N F O}

\section{Article history:}

Received 7 July 2014

Accepted 11 August 2014

Published 20 March 2015

\section{Keywords:}

Silver nanoparticle

Calix $[n]$ arene

Flutamide

Voltammetric sensor

\begin{abstract}
A B S T R A C T
Ag nanoparticles were synthesized on the surface of a glassy carbon electrode modified with $p$-tert-butylcalix[4]arene and p-tert-butylcalix[6]arene by the deposition of $\mathrm{Ag}^{+}$at an open circuit potential followed by the electrochemical reduction of the $\mathrm{Ag}^{+}$. The presence of the calixarene layer on the electrode surface controlled the particle size and prevented agglomeration. Cyclic voltammetry showed that the Ag nanoparticles on the modified glassy carbon electrode had good catalytic ability for the reduction of flutamide. The effects of calixarene concentration, potential applied for the reduction of $\mathrm{Ag}^{+}$, number of calixarene layers, and $\mathrm{pH}$ value on the electrocatalytic activity of the $\mathrm{Ag}$ nanoparticles were investigated. The modified electrode had a linear range in differential pulse voltammetry of $10-1000 \mu \mathrm{mol} / \mathrm{L}$ with a detection limit of $9.33 \mu \mathrm{mol} / \mathrm{L}$ for flutamide at an $S / N=3$. The method was applied to the detection of flutamide in practical samples.
\end{abstract}

(C) 2015, Dalian Institute of Chemical Physics, Chinese Academy of Sciences.

Published by Elsevier B.V. All rights reserved.

\section{Introduction}

Flutamide (FLT), 4-nitro-3-trifluoromethyl-isobutilanilide, is a widely used nonsteroidal anti-androgen drug for the treatment of prostate cancer. FLT and other anti-androgens block the male hormone, testosterone, which stimulates the growth of prostate cancer cells. The prostate cancer cells are unable to grow without testosterone. FLT does not cure prostate cancer, but it can keep the cancer under control for many months or years [1,2]. FLT has also been used in the treatment of male-to-female transsexuals. After human oral administration, FLT is quickly metabolized to produce about 10 metabolites, mainly 2-hydroxyflutamide and 3-trifluoromethyl4-nitroaniline [3].

There are limited methods for the selective detection of FLT, which are flow injection [4], spectrophotometric [5,6] and electrochemical $[7,8]$ methods, and high performance liquid chromatography (HPLC) [9]. These methods suffer from different problems. The flow injection method has a high limit of detection (LOD), the spectrophotometric and HPLC methods do not have specific LODs, and the electrochemical methods use a dropping mercury electrode that is hazardous to the environment. In the present study, we developed a sensitive and rapid method with a low LOD for the detection of FLT in practical samples using electrochemical methods, which gave the advantageous of simplicity and sensitivity. Electrochemical methods such as differential pulse polarography [10], stripping voltammetry [11], differential pulse voltammetry [12], and square-wave voltammetry [13] have been widely applied for the detection of pharmaceuticals.

In recent years, particular modification methods that can activate the surface of a glassy carbon electrode (GCE) with

*Corresponding author. Tel: +98-112-5342392; Fax: +98-112-5342350; E-mail: j.raoof@umz.ac.ir 
respect to a specific electrochemical reaction in the solution have been reported. Among the different materials used as modifier, metal nanoparticles have attracted considerable attention and have been widely used due to their novel structural, electronic, and chemical properties. Several metal nanoparticle-modified electrodes have been employed to determine the concentration of drugs in practical samples. For example, $\mathrm{Pt}$ [14], $\mathrm{Au}$ [15], and Ag nanoparticles [16] were used to determine phenobarbital, L-cystein, and dopamine, respectively. Some methods have been reported for the synthesis of Ag nanoparticles at the surface of a GCE $[17,18]$. Song et al. [17] used cefopernazone as a stabilizing reagent. From the scanning electron microscope (SEM) images, the Ag nanoparticles synthesized by their method were larger than those synthesized by our method. Raoof et al. [18] used $p$-isopropyl calix[6]arene as a template for the synthesis of Ag nanoparticles. However, in the present study, we used $p$-tert-butylcalix[4]arene that gave Ag nanoparticles with a smaller size. Therefore, the surface area of the GCE and the catalytic activity were increased by our method with respect to the other methods.

Calixarenes are macrocyclic compounds composed of phenolic units connected by methylene bridges that form hydrophobic cavities. They belong to the class of cavitands known for their host-guest chemistry. They are simple to prepare in high yields from inexpensive starting compounds and are easy to modify $[19,20]$. In addition to their inclusion capability, which makes them potential "nanoscale containers", the other properties of calixarenes and their low cost and non-toxicity allow their use in many areas as catalysts [21], extractants [22], semiconductor materials [23], and sensors of bioactive compounds [24]. The history of calixarenes extends back to the work of Adolph von Bayer in 1872 [25] when they were first synthesized as the products of the reaction of phenols with aldehydes in the presence of strong acids. Among the various calix $[n]$ arenes, $p$-tert-butylcalix[4]arene and $p$-tert-butylcalix[6]arene possess good coordination ability for $\mathrm{Ag}^{+}$due to their suitable cavity size.

The electrochemical detection of FLT using a glassy carbon electrode modified with nano-Ag (nano-Ag/MGCE) has not been reported. In this paper, $p$-tert-butylcalix[4]arene and $p$-tert-butylcalix[6]arene were used as the template for the synthesis of Ag nanoparticles at the surface of a GCE. The synthesis of nano-Ag by this method was very easy and controllable. The effects of different parameters (calixarene concentration, applied potential, $\mathrm{pH}$, and $p$-tert-butylcalix[4 or 6]arene layer numbers) on the activity of the modified electrode for the reduction of FLT were studied. The modified electrode was applied for the detection of FLT in practical samples.

\section{Experimental}

\subsection{Chemicals and reagents}

p-tert-Butylcalix[4]arene and p-tert-butylcalix[6]arene were synthesized according to the Gutsche method [26,27]. $\mathrm{AgNO}_{3}$ was purchased from Fluka. Phosphate buffer solutions (PBS) of $0.1 \mathrm{~mol} / \mathrm{L}$ were prepared by mixing stock solutions of 0.1
mol/L $\mathrm{NaH}_{2} \mathrm{PO}_{4}$ and $\mathrm{Na}_{2} \mathrm{HPO}_{4}$ to give different $\mathrm{pH}$ values. The biological samples were obtained from Dr. Safiri Medical Diagnostic Laboratory, Babolsar, Iran. Other reagents were analytical grades purchased from Merck and used as received. Stock solutions of FLT were freshly prepared as required in the PBS (0.1 mol/L; $\mathrm{pH}=4,5,6,7,8$, and 9).

\subsection{Apparatus}

Electrochemical measurements were performed using a potentiostat and galvanostat (Model Autolab, PGSTAT30, Eco chemie, Netherlands) connected to a Pentium IV personal computer (with GPES software for voltammetry and differential pulse voltammetry). A conventional three electrode system was employed with a platinum wire as the counter (or auxiliary) electrode and a saturated calomel electrode (SCE) as the reference electrode. A glassy carbon disk electrode (Azar Electrode Co., Iran) with a geometrical area of $0.025 \mathrm{~cm}^{2}$ was used as the working electrode. All experiments were performed at room temperature $\left(25 \pm 2{ }^{\circ} \mathrm{C}\right)$. A digital $\mathrm{pH}$ meter $(780$ $\mathrm{pH}$-meter, Metrohm) with precision of \pm 0.001 was used to read the $\mathrm{pH}$ value of the buffer solutions. Electrolyte solutions were deoxygenated by purging with nitrogen (99.999\%) for $10 \mathrm{~min}$ prior to the electrochemical experiments. All measurements were carried out under $\mathrm{N}_{2}$ atmosphere. The nanostructure and morphology of the synthesized nanoparticles were determined by VEGA-Tescan SEM.

\subsection{Preparation of nano-Ag/MGCE}

Prior to modification, pretreatment of the GCE was performed using $0.05 \mathrm{~mm}$ alumina slurry on a polishing cloth, followed by rinsing thoroughly with distilled water and sonication in a mixture of ethanol and water $(1: 1 v / v)$ for $5 \mathrm{~min}$. $p$-tert-Butylcalix[4]arene and $p$-tert-butylcalix[6]arene solutions $(0.01 \mathrm{~mol} / \mathrm{L})$ in toluene and chloroform, respectively, were dropped onto the surface of the cleaned GCE and dried at room temperature. The electrode was then immersed in 1.0 mmol/L of $\mathrm{AgNO}_{3}$ for $10 \mathrm{~min}$. The accumulated $\mathrm{Ag}^{+}$was electrochemically reduced for $25 \mathrm{~s}$ at $-0.3 \mathrm{~V}$ versus the SCE. The dropping, immersing, and electrochemical reduction of $\mathrm{Ag}^{+}$ were carried out 3 times because the electrode modified with three layers of $p$-tert-butylcalix[4 or 6]arene showed the best activity for the reduction of FLT. Finally, the calixarene layer was removed from the surface of the electrode by immersing the modified electrode in stirred pure toluene (when p-tert-butylcalix[4]arene was the template) or chloroform (when $p$-tert-butylcalix[6]arene was the template) for $15 \mathrm{~min}$. The nano-Ag/MGCE prepared was used for further experiments.

\section{Results and discussion}

\subsection{Characterization of nano- $\mathrm{Ag} / \mathrm{GCE}$}

The oxidation-reduction behavior of the Ag nanoparticles at the surface of the modified electrode was used to obtain evi- 


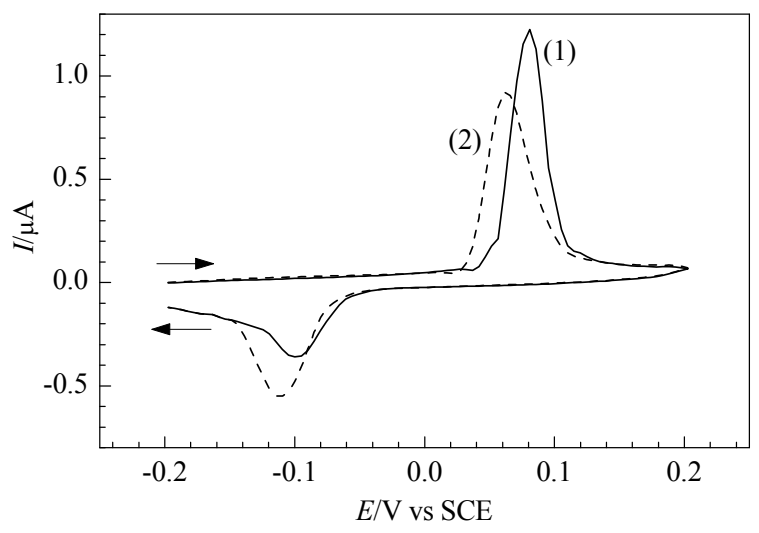

Fig. 1. Cyclic voltammogram of Ag nanoparticles on the modified GCE using $p$-tert-butylcalix[4]arene (1) and $p$-tert-butylcalix[6]arene (2) as template in $0.1 \mathrm{~mol} / \mathrm{L} \mathrm{PBS}(\mathrm{pH}=7.0)$ at a scan rate of $50 \mathrm{mV} / \mathrm{s}$.

dence for the formation of nanoparticles. Figure 1 shows the cyclic voltammogram of the nano-Ag/MGCE in $0.1 \mathrm{~mol} / \mathrm{L} \mathrm{PBS}$ at pH 7.0. The nano-Ag/MGC electrode exhibited a clear anodic peak with a peak potential of $+0.08 \mathrm{~V}$ vs SCE, which is the characteristic oxidation peak of Ag nanoparticles. A small reduction peak appeared at the potential of $-0.1 \mathrm{~V}$ vs SCE, which was associated with the reduction of $\mathrm{Ag}^{+}$cations.

The surface morphology and distribution of Ag nanoparticles at the surface of the GCE were further studied using SEM. Figure 2 depicts the 3D matrix structure of the electrode surface obtained during different steps of the modifying process with $p$-tert-butylcalix[4]arene as template. Figure 2(a) shows the surface of the bare GCE after polishing, and Fig. 2(b) exhibits the structure of the $p$-tert-butylcalix[4]arene layer after the deposition of $\mathrm{Ag}$ on the electrode. Figure 2(c) depicts the structure of the surface of nano-Ag/MGCE after deposition of the calixarene layer. It was clearly seen that the Ag nanoparti-
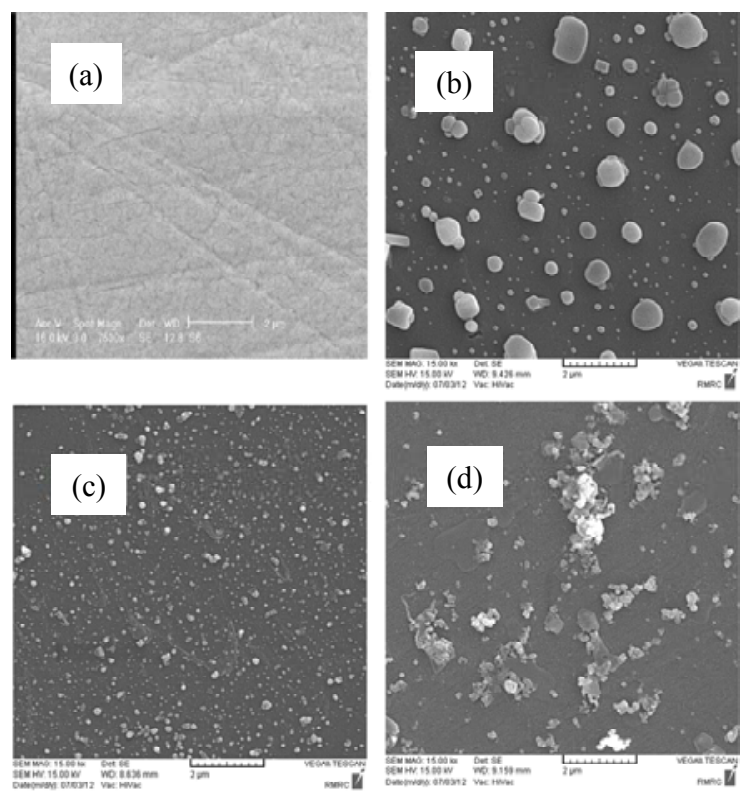

Fig. 2. SEM images of bare GCE (a), nano-Ag/calixarene/GCE (b), nano-Ag/MGCE (c), and Ag/GCE (d). cles have a homogeneous distribution at the surface of the electrode. To prove the use of the $p$-tert-butylcalix[4]arene layer as a nano-scale template, bare GCE was immersed in Ag$\mathrm{NO}_{3}$ solution, and $\mathrm{Ag}^{+}$was deposited at the surface of the GCE. The adsorbed $\mathrm{Ag}^{+}$at the bare GCE formed large Ag blocks with irregular shapes as shown in Fig. 2(d). The results implied that in the absence of a calixarene film, $\mathrm{Ag}$ atoms produced from the electroreduction of $\mathrm{Ag}^{+}$preferentially grew on the deposited $\mathrm{Ag}$ nuclei to form large blocks. On the other hand, calixarene acted as a template on the electrode surface leading to a large increase in the quantity of $\mathrm{Ag}$ nanoparticles and a decrease in their size with the prevention of aggregation of $\mathrm{Ag}$ atoms into large blocks. Hence, the calixarene film controlled the size, quantity, and distribution of the Ag nanoparticles produced.

\subsection{Electrocatalytic behavior of FLT at the GCE and nano-Ag/GCE}

Both $p$-tert-butylcalix[4] arene and $p$-tert-butylcalix[6]arene have a suitable ring size for entangling $\mathrm{Ag}^{+}$. Thus, both were employed as the template in the synthesis of Ag nanoparticles at the surface of the GCE. The results were compared using the reduction of FLT. The cyclic voltammograms of FLT at a bare GCE and nano-Ag/MGCEs in $0.1 \mathrm{~mol} / \mathrm{L}$ of PBS (pH = 6.0) at a scan rate of $50 \mathrm{mV} / \mathrm{s}$ are shown in Fig. 3. These results implied that FLT reduction at the bare GCE was slow due to the slow electron transfer while the activity was considerably improved with the nano-Ag/MGCEs. The peak potential due to the reduction of FLT at the surface of the bare GCE was $-0.7 \mathrm{~V}$ vs SCE with a peak current of $-0.55 \mu \mathrm{A}$. On the other hand, the reduction potentials of FLT at the surface of nano-Ag/MGCE with $p$-tert-butylcalix[4]arene and p-tert-butylcalix[6]arene as template were decreased to -0.64 and $-0.66 \mathrm{~V}$ vs SCE, and the peak currents were enhanced to -2.64 and $-1.40 \mu \mathrm{A}$, respectively. The enhancement in peak current and shift to a less negative potential with the nano-Ag/MGCE were attributed to the catalytic activity of the nano-Ag particles for the reduction of FLT. The large catalytic current was ascribed to the large number of

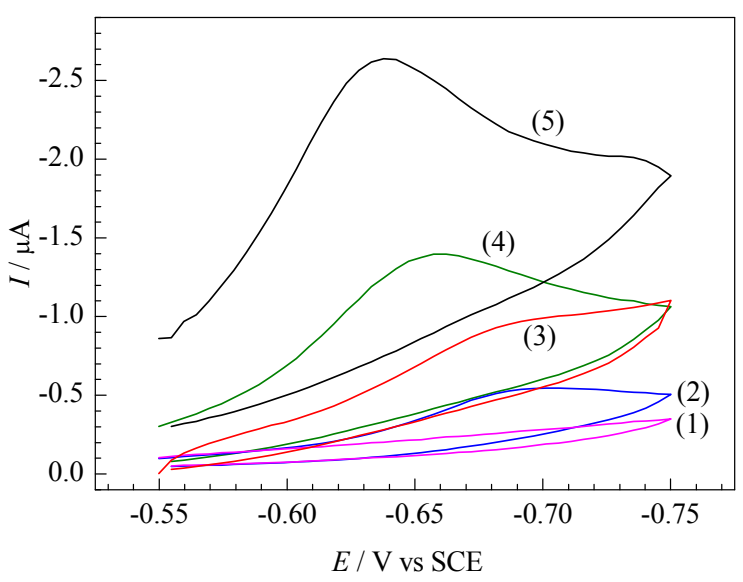

Fig. 3. Cyclic voltammograms of bare GCE in the absence (1) and presence (2) of $1.0 \mathrm{mmol} / \mathrm{L}$ FLT in $0.1 \mathrm{~mol} / \mathrm{L} \mathrm{PBS}$ at pH 6.0. Cyclic voltammograms of nano-Ag/GCE ((4) and (5)) and Ag/GCE (3) in $0.1 \mathrm{~mol} / \mathrm{L}$ PBS at pH 6.0 in the presence of $0.2 \mathrm{mmol} / \mathrm{L}$ FLT. Scan rate: $50 \mathrm{mV} / \mathrm{s}$. 
small Ag nanoparticles at the surface of the electrodes, which gave a large surface area.

\subsection{Optimization of the parameters for the detection of FLT}

To find the optimum conditions for FLT detection at the nano-Ag/MGCEs, the experimental conditions were optimized. The effect of calixarene layer number is illustrated in Fig. 4. The peak current of FLT reduction at the surface of nano-Ag/MGCE increased with increasing calixarene layers from one to three. The electrode that was modified with three layers of calixarene gave the best FLT voltammetric detection. The reason is that an increase in calixarene layers enhanced the amount of nanoparticles on the surface of the GCE so that the catalytic activity of the nano-Ag/MGCE for FLT reduction was improved. However, with a further increase in the layer number of calixarene, a decrease in catalytic activity was observed. This was due to an increase in the thickness of the calixarene film on the GCE and a decrease in its conductivity.

The calixarene concentration had a large influence on the peak current as shown in Fig. 5. The voltammetric response of the sensor was enhanced with increasing calixarene concentration and reached its maximum at the concentration of 0.01

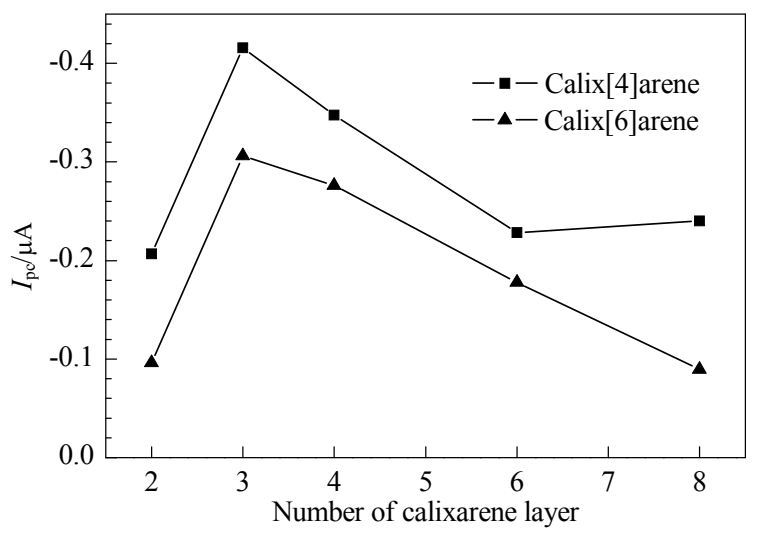

Fig. 4. Effect of calixarene layer number on the cyclic voltammetric responses of the nano-Ag/MGCE in the presence of $0.2 \mathrm{mmol} / \mathrm{L} \mathrm{FLT} \mathrm{in}$ $0.1 \mathrm{~mol} / \mathrm{L} \mathrm{PBS}(\mathrm{pH} 7.0$ ) at a scan rate of $20 \mathrm{mV} / \mathrm{s}$.

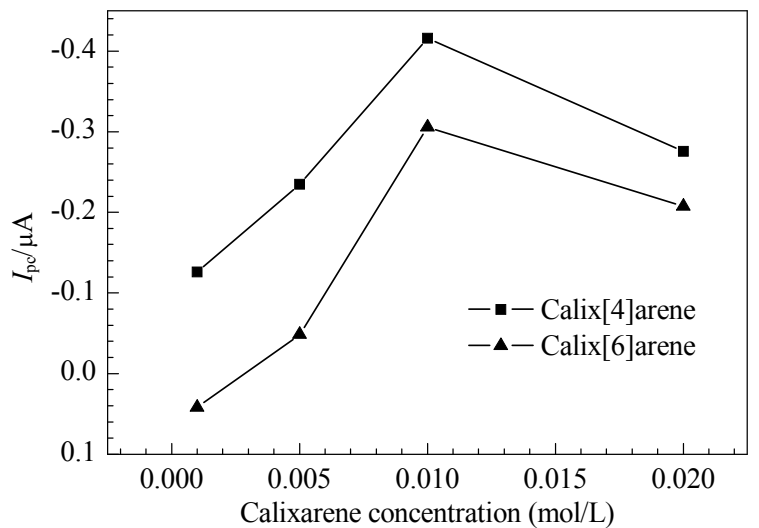

Fig. 5. Effect of calixarene concentration on the cyclic voltammetric responses of nano-Ag/MGCE in the presence of $0.2 \mathrm{mmol} / \mathrm{L}$ FLT in 0.1 $\mathrm{mol} / \mathrm{L} \mathrm{PBS}(\mathrm{pH} 7.0$ ) at a scan rate of $20 \mathrm{mV} / \mathrm{s}$.
mol/L, while with higher concentrations, the cathodic peak current was decreased. This phenomenon was explained by the following. At a low concentration of calixarene, a small amount of Ag nanoparticles was deposited at the surface of the electrode leading to a low current. With too high a calixarene concentration, some calixarene remained at the surface of the electrode after the dissolving of its layer, which decreased the electrode conductivity.

The applied potential ( $E_{\mathrm{app}}$ ) for the reduction of $\mathrm{Ag}^{+}$on calixarene-modified GCE was studied as another electrode parameter. The maximum peak current of FLT was observed at -0.3 V vs SCE (Fig. 6).

The FLT redox behavior depended on the $\mathrm{pH}$ value of the buffer solution. Therefore, the effect of the $\mathrm{pH}$ of the solution was investigated by cyclic voltammetry over the $\mathrm{pH}$ range of 4.0-9.0 (Fig. 7). The results showed that the cathodic potential of FLT shifted to more negative values with increasing $\mathrm{pH}$, indicating that the electrocatalytic reduction of FLT at the surface of the modified electrode involved a proton reaction. The relationship between the peak potential and $\mathrm{pH}$ value was fitted to the regression equation $E_{\mathrm{p}}=-0.0299 \mathrm{pH}-0.4438$ with a correlation coefficient of $R^{2}=0.9951$ for $p$-tert-butylcalix[4]arene, and $E_{\mathrm{p}}=-0.0332 \mathrm{pH}-0.4209$ and $R^{2}=0.9777$ for $p$-tert-butylcalix[6]arene. The slopes were -0.0299 and $-0.0332 \mathrm{~V} / \mathrm{pH}$ for p-tert-butylcalix[4]arene and p-tert-butylcalix[6]arene, respectively, in the studied $\mathrm{pH}$ range. The results showed that the cathodic peak current of FLT had its maximum at $\mathrm{pH}=6.0$.

According to the slope of the potential vs $\mathrm{pH}$ plot, in the electrocatalytic reduction of FLT at the nano-Ag/MGCE, four electrons and two protons were involved. The mechanism is shown in Scheme 1.

The highest peak current was obtained with the following parameters: $p$-tert-butylcalix[4]arene as template, 3 layers of calixarene, $0.01 \mathrm{mmol} / \mathrm{L}$ of calixarene concentration, $-0.3 \mathrm{~V}$ vs SCE applied potential, and $\mathrm{pH}=6.0$. Two templates were used in this work, $p$-tert-butylcalix[4]arene and p-tert-butylcalix[6]arene. They gave different results, and the better result was obtained with $p$-tert-butylcalix[4]arene. The reason was probably that $p$-tert-butylcalix[4]arene had the smaller ring size. Therefore, when using $p$-tert-butylcalix[4]arene as the

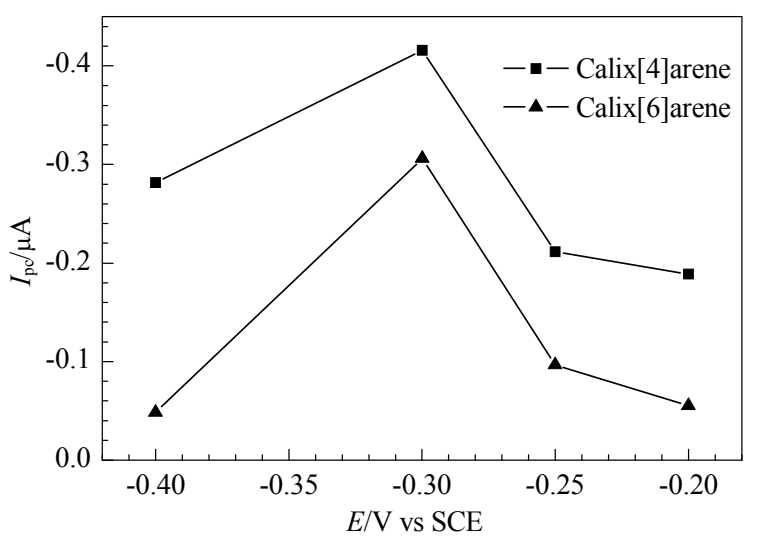

Fig. 6. Effect of applied potential for the reduction of $\mathrm{Ag}^{+}$from the cyclic voltammetric responses of nano-Ag/MGCE in the presence of 0.2 $\mathrm{mmol} / \mathrm{L}$ FLT in PBS (pH 7.0, $0.1 \mathrm{~mol} / \mathrm{L}$ ) at a scan rate of $20 \mathrm{mV} / \mathrm{s}$. 

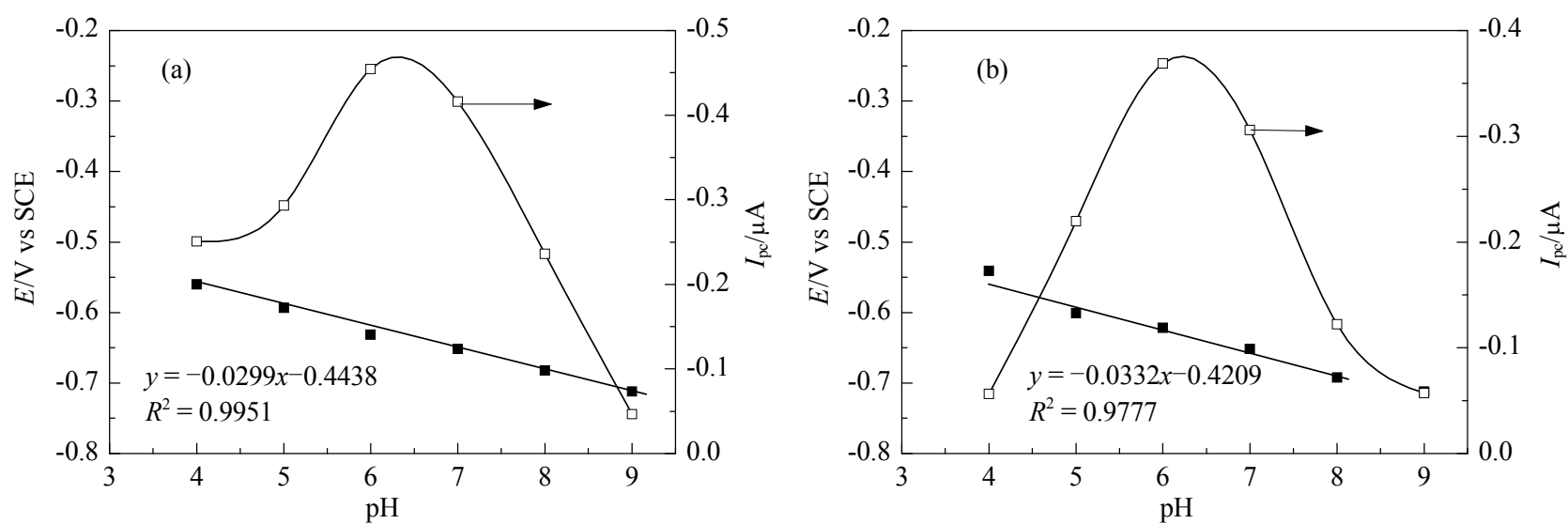

Fig. 7. Effect of $\mathrm{pH}$ values on the peak current and peak potential of the cyclic voltammetric responses of nano-Ag/MGCE in the presence of 0.2 $\mathrm{mmol} / \mathrm{L} \mathrm{FLT} \mathrm{with} \mathrm{pH} \mathrm{value} \mathrm{(4.0-9.0)} \mathrm{at} \mathrm{a} \mathrm{scan} \mathrm{rate} \mathrm{of} 20 \mathrm{mV} / \mathrm{s}$. (a) Calix[4]arene; (b) Calix[6]arene.<smiles>CC(C)C(=O)Nc1ccc([N+](=O)[O-])c(C(F)(F)F)c1</smiles>

Scheme 1. Electrochemical reduction of flutamide.

template, Ag nanoparticles with a smaller size were synthesized. Therefore, the surface area was enhanced more.

\subsection{Effect of potential scan rate}

The dependence of the FLT peak current on the scan rate of the potential $(v)$ under the optimal conditions was investigated in the range of $10-200 \mathrm{mV} / \mathrm{s}$. Figure 8 shows the cyclic voltammograms of $0.2 \mathrm{mmol} / \mathrm{L}$ FLT at nano-Ag/MGCE at the different scan rates. The peak current was proportional to $v$ according to the regression equation $I_{\mathrm{p}}(\mu \mathrm{A})=-0.0128 \mathrm{v}(\mathrm{mV} / \mathrm{s})-$ 0.6349 with a correlation coefficient of $R^{2}=0.997$. This result indicated that the electrochemical process was surface reaction-controlled. Moreover, the peak potential of FLT was shifted to more negative values with increasing $v$. This can be associated with electrochemical limitation at the surface of the electrode.

The data derived from the rising part of the voltammogram at $v=10 \mathrm{mV} / \mathrm{s}$, called the Tafel plot, was employed to obtain more information about the rate determining step. This part of voltammograms is affected by the electron transfer kinetics between the electroactive species and the surface of the modified electrodes [28]. The slope of Tafel plot was $-5.0278 \mathrm{dec}-$ $a^{-1}$ for the reduction of FLT which was equal to $-\alpha n_{\alpha} F / 2.3 R T$. Also, $n_{\alpha}=0.3$. Assuming $n=1$, then $\alpha$ (transfer coefficient) was 0.3 .

For an irreversible electrode process, according to Laviron law [29], $E_{\mathrm{p}}$ is defined by $E_{\mathrm{p}}=E^{0^{\prime}}+(2.303 R T / \alpha n F) \log$ $\left(R T k^{0} / \alpha n F\right)+(2.303 R T / \alpha n F) \log v$, where $\alpha$ is the transfer coefficient, $k^{0}$ is the standard heterogeneous rate constant for the reaction of FLT, $n$ is the number of electrons transferred, $v$ is the scan rate of the potential, and $E^{0}$ is the formal redox potential. The other symbols have their usual meanings. The plot of $E_{\mathrm{p}}$ vs $\log v$ was linear with an intercept that allowed $k^{0}$ to be determined when the value of $E^{0^{\prime}}$ was known. The value of $E^{0^{\prime}}$ was obtained from the intercept of the $E_{\mathrm{p}}$ vs $v$ curve by extrapolating to the vertical axis at $v=0$. For the reduction of FLT at the surface of the modified electrode, $E^{0^{\prime}}$ was $-0.65 \mathrm{~V}$ vs SCE, and $k^{0}$ was calculated to be $16.7 \mathrm{~s}^{-1}$.

\subsection{Calibration curve and limit of detection}

The differential pulse voltammetric response of the modified electrode to the FLT reduction was investigated under the optimized conditions. Figure 9 shows typical differential pulse voltammograms obtained with increasing FLT concentration leading to a linear increase in the peak current. The results indicated a wide linear range between the differential pulse voltammetric current and concentration of FLT. The linear relationship covered two FLT concentration ranges: 10-100

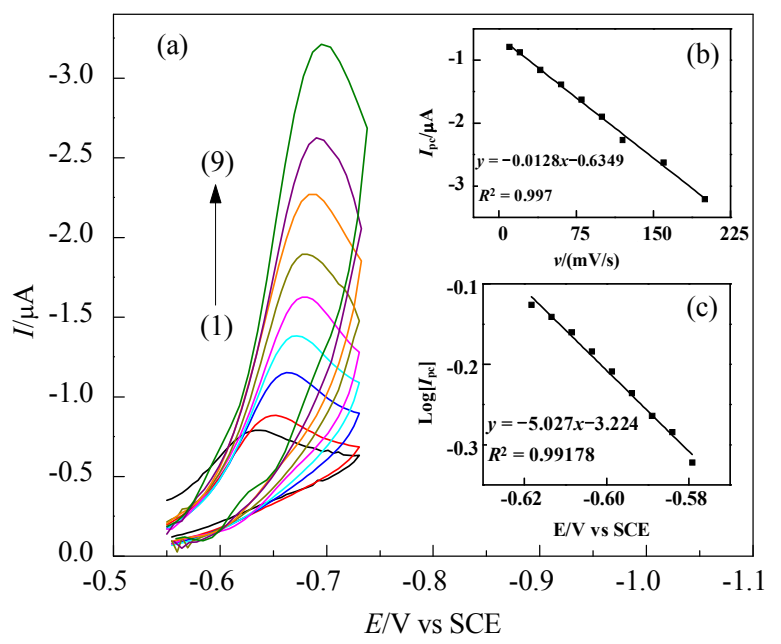

Fig. 8. (a) Cyclic voltammograms of nano-Ag/MGCE in the presence of $0.2 \mathrm{mmol} / \mathrm{L}$ FLT in PBS (pH 6.0, $0.1 \mathrm{~mol} / \mathrm{L}$ ) at different scan rates of the potential; the numbers (1)-(9) are for scan rates of 10, 20, 40, 60, 80, $100,120,160$, and $200 \mathrm{mV} / \mathrm{s}$; (b) Variation of $I_{\mathrm{pc}} \mathrm{Vs} v$; (c) Tafel plot at a scan rate of $10 \mathrm{mV} / \mathrm{s}$. 


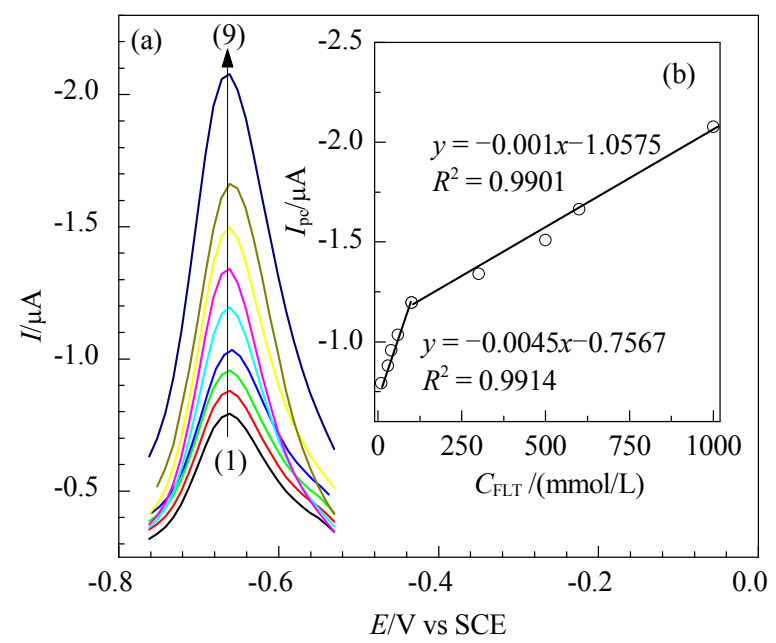

Fig. 9. Differential pulse voltammograms of nano-Ag/MGCE in 0.1 $\mathrm{mol} / \mathrm{L}$ PBS (pH 6.0) for different concentrations of FLT. Numbers (1)-(9 are for $10,30,40,60,100,300,500,600$, and $1000 \mathrm{mmol} / \mathrm{L}$ of FLT. The inset shows the plot of the electrocatalytic peak current as a function of the FLT concentration.

$\mu \mathrm{mol} / \mathrm{L}$ which could be fitted to the regression equation of $I_{\mathrm{p}}=$ $-0.0045 C_{\text {FLT }}-0.7567\left(R^{2}=0.9914, C_{\text {FLT }}\right.$ is in $\left.\mu \mathrm{mol} / \mathrm{L}\right)$, and $100-1000 \mu \mathrm{mol} / \mathrm{L}$ which could be fitted to the regression equation of $I_{\mathrm{p}}=-0.001 C_{\mathrm{FLT}}-1.0575\left(R^{2}=0.9901, C_{\mathrm{FLT}}\right.$ is in $\left.\mu \mathrm{mol} / \mathrm{L}\right)$. The detection limit $(S / N=3)$ in the lower linear range was 9.33 $\mu \mathrm{mol} / \mathrm{L}$.

Although other research groups have reported on the electrochemical detection of FLT in pharmaceutical formulations which have a lower LOD $[7,8]$, these methods have disadvantages. For example, Reddy et al. [7] and Lvarez-Lueje et al. [8] reported the use of a dropping mercury electrode for detection of FLT. This method is unattractive because the mercury electrode is toxic and hazardous to the environment [30]. Hence, these methods do not allow the direct analysis of FLT in practical samples. Many researchers have used nano-Ag as a modifier for the detection of biological compounds [16,31]. Here, for the first time, we have proposed an electrochemical method for FLT detection, which is not dangerous for the environment.

\subsection{Interference studies}

Under the optimum experimental conditions, the possible interference agents (dopamine, ascorbic acid, L-dopa, epinephrine, tryptophan, L-cysteine, uric acid) were investigated for the voltammetric detection of FLT at the surface of nano-Ag/MGCE. The experimental results (Table 1) showed that the modified electrode yielded only a small change in the response for interfering agents at the same concentration level. This confirmed that nano-Ag/MGCE could be used as a good electrochemical sensor for FLT.

\subsection{Practical sample analysis}

The method was applied for the voltammetric detection of
Table 1

Effect of interference agent on the voltammetric detection of FLT with nano-Ag/MGCE.

\begin{tabular}{lcc}
\hline Interfering agent & Concentration $(\mu \mathrm{mol} / \mathrm{L})$ & Signal change $(\%)$ \\
\hline Dopamine & 10 & +0.2 \\
Ascorbic acid & 100 & 0.0 \\
L-Dopa & 10 & -0.1 \\
Epinephrine & 10 & +1.0 \\
Tryptophan & 20 & 0.0 \\
L-cysteine & 20 & 0.0 \\
Uric acid & 100 & 0.0 \\
\hline
\end{tabular}

FLT in medicine tablets and urine samples by the standard addition method $(n=5)$. The results demonstrated the capability of the modified electrode for the voltammetric detection of FLT in practical samples.

\subsubsection{Detection of FLT in medicine tablets}

The flutamide tablet ( 2 tablets, $250 \mathrm{mg}$, from Mehr Darou Pharmaceutical Co., Tehran, Iran) was finely grinded in a mortar with a pestle. The powder obtained was dissolved in 100 $\mathrm{mL}$ distilled water by ultrasonication. Different adequate amount of prepared solution was diluted to $10 \mathrm{~mL}$ with 0.1 mol/L of phosphate buffer ( $\mathrm{pH}$ 6.0) and transferred to the voltammetric cell for voltammetric detection by the standard addition method. The results are presented in Table 2 .

\subsubsection{Analysis of FLT in human urine sample}

For preparing the urine sample, normal urine samples (ca. 5 $\mathrm{mL}$ ) were obtained from three healthy volunteers (male, seventeen years old) from a single morning urination. A solution of $\mathrm{NaOH}(0.1 \mathrm{~mol} / \mathrm{L})$ was added to the urine samples. The mixture was vortexed for $3 \mathrm{~min}$, after which $3 \mathrm{~mL}$ of ethylacetate was added and then the mixture was vortexed for an additional 3 min. Finally, it was centrifuged at $3000 \mathrm{r} / \mathrm{min}$ for $10 \mathrm{~min}$ to separate the aqueous and organic layers. The residual aqueous phase was reconstituted with the phosphate buffer solution at pH 6.0 and used for analytical detection. The results are given in Table 3. Satisfactory experimental results were found for FLT. The reproducibility of the method was demonstrated by the mean relative standard deviation (RSD).

Table 2

Electrochemical detection of FLT in a pharmaceutical sample $(n=5)$ at nano-Ag/MGCE.

\begin{tabular}{lcccc}
\hline Sample & Added $(\mu \mathrm{mol} / \mathrm{L})$ & Found $(\mu \mathrm{mol} / \mathrm{L})$ & Recovery $(\%)$ & RSD $(\%)$ \\
\hline FLT & 20.0 & 20.4 & 102.0 & 1.30 \\
& 40.0 & 40.1 & 100.2 & 0.04 \\
& 100.0 & 100.2 & 100.2 & 0.06 \\
\hline
\end{tabular}

Table 3

Detection of FLT in urine samples at the surface of nano-Ag/MGCE.

\begin{tabular}{lcccc}
\hline Sample & Spiked $(\mu \mathrm{mol} / \mathrm{L})$ & Found $(\mu \mathrm{mol} / \mathrm{L})$ & Recovery $(\%)$ & RSD $(\%)$ \\
\hline Urine & 0.0 & - & - & - \\
& 20.0 & 19.8 & 99.0 & 1.3 \\
& 60.0 & 59.7 & 99.5 & 1.8 \\
& 80.0 & 80.1 & 100.1 & 1.9 \\
& 120.0 & 121.0 & 100.9 & 2.6 \\
\hline
\end{tabular}




\section{Graphical Abstract}

Chin. J. Catal., 2015, 36: 439-445 doi: 10.1016/S1872-2067(14)60209-6

Synthesis of Ag nanoparticles for the electrochemical detection of anticancer drug flutamide

Farzaneh Ahmadi, Jahan Bakhsh Raoof*, Reza Ojani, Mehdi Baghayeri, Moslem Mansour Lakouraj, Hamed Tashakkorian University of Mazandaran, Iran
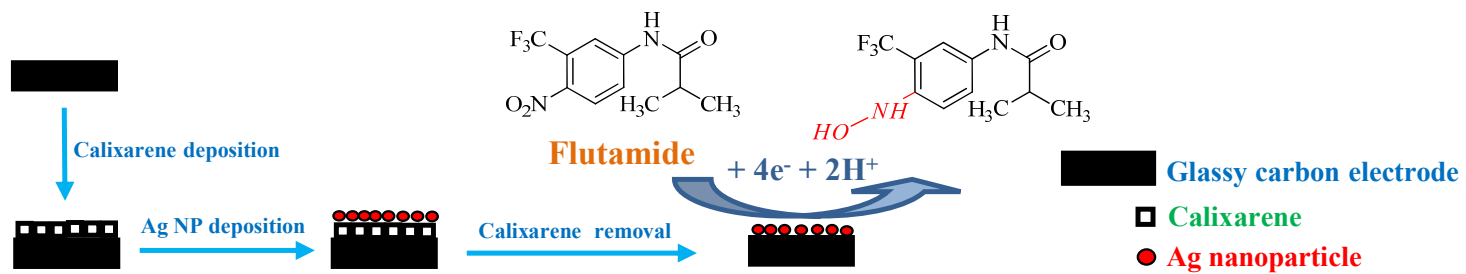

A simple and fast electrochemical synthesis of silver nanoparticles using calixarene as template was used for flutamide detection.

\section{Conclusions}

A sensitive and low cost method for the voltammetric detection of FLT was reported. Calixarene was used as the template for synthesizing Ag nanoparticles at the surface of a GCE. The use of calixarene gave highly dispersed and homogenous nano-Ag particles. This modified electrode showed excellent electrocatalytic response for FLT under the optimized conditions ( $p$-tert-butylcalix[4]arene used as template, calixarene concentration $=0.01 \mathrm{~mol} / \mathrm{L}, \mathrm{pH}$ of PBS $=6.0$, calixarene layers $=$ 3 , and the applied potential for the reduction of $\mathrm{Ag}$ cations = -0.3 vs SCE). This modified electrode was also used for the detection of FLT in practical samples.

\section{References}

[1] Brogden R N, Chrisp P. Drugs Aging, 1991, 1:104

[2] Small E J. Curr Opin Oncol, 1997, 9: 277

[3] Jonler M, Riehmann M, Bruskewitz R C. Drugs, 1994, 47: 66

[4] Tzanavaras P D, Themelis D G. J Pharm Biomed Anal, 2007, 43: 1820

[5] Nagaraja P, Sunitha K R, Silwadi M F. J Pharm Biomed Anal, 2000, 23: 617

[6] Nagaraja P, Arun Kumar H R, Vasantha R A, Yathirajan H S. Int J Pharm, 2002, 235: 113

[7] Reddy G V S, Reddy C L N, Myreddy V N, Reddy S J. J Clin Med Res, 2011, 3(3): 35

[8] Alvarez-Lueje A, Pena C, Nunez-Vergara L J, Squella J A. Electroanalysis, 1998, 10: 1043

[9] Farthing D, Sica D, Fakhry I, Walters D L, Cefali E A, Allan G. Biomed Chromatogr, 1994, 8: 251

[10] Raoof J B, Ojani R, Baghayeri M, Ahmadi F. Anal Methods, 2012, 4: 1825
[11] Lichtig J, Andrade R F, Vaz J M. Anal Chim Acta, 1996, 332: 161

[12] Mazloum-Ardakani M, Abolhasani M, Mirjalili B F, Sheikh-Mohseni M A, Dehghani-Firouzabadi A, Khoshroo A. Chin J Catal (催化学 报), 2014, 35: 201

[13] Ensafi A A, Bahrami H, Karimi-Maleh H, Mallakpour S. Chin J Catal (催化学报), 2012, 33: 1919

[14] Raoof J B, Baghayeri M, Ojani R. Colloids Surf B, 2012, 95: 121

[15] Ojani R, Raoof J B, Maleki A A, Safshekan S. Chin J Catal (催化学 报), 2014, 35: 423

[16] Tashkhourian J, Nezhad M R H, Khodavesi J, Javadi S. J Electroanal Chem, 2009, 633: 85

[17] Song Y Z, Ma K R, Zhu F X, Cheng Z P, Song Y, Dai B L, Xu J. Int J Electrochem Sci, 2013, 8: 3628

[18] Raoof J B, Ojani R, Hasheminejad E, Rashid-Nadimi S. Appl Surf Sci, 2012, 258: 2788

[19] Gutsche C D. Acc Chem Res, 1983, 16: 161

[20] Gutsche C D. Top Curr Chem, 1984, 123: 1

[21] Wieser C, Dieleman C B, Matt D. Coord Chem Rev, 1997, 165: 93

[22] Casnati A, Barboso S, Rouquette H, Schwing-Weill M J, Arnaud-Neu F, Dozol J F, Ungaro R. J Am Chem Soc, 2001, 123: 12182

[23] Ohnishi Y, Fujita J, Ochiai Y, Matsui S. Microelectron Eng, 1997, 35: 117

[24] Wei A. Chem Commun, 2006: 1581

[25] Von Baeyer A. Ber Dtsch Chem Ges, 1872, 5: 25

[26] Gutsche C D. Calixarenes Revisited. London: Royal Society of Chemistry, 1998

[27] Gutsche C D, Dhawan B, No K H, Muthukrishnan R. J Am Chem Soc, 1981, 103: 3782

[28] Bard A J, Faulkner L R. Electrochemical Methods: Fundamentals and Applications. 2nd Ed. New York: John Wiley \& Sons Inc, 2000

[29] Laviron E. J Electroanal Chem Interfacial Electrochem, 1979, 101: 19

[30] Wang J. Analytical Electrochemistry. New York: Wiley-VCH, 2000

[31] Zhang Y Z, Zhang K Y, Ma H Y. Anal Biochem, 2009, 387: 13 